\title{
Drug use among drivers who drank on alcohol outlets from Porto Alegre, Brazil
}

\author{
Raquel B. De Boni ${ }^{a}$,*, Francisco Inacio Bastos ${ }^{\mathrm{a}}$, Mauricio de Vasconcellos ${ }^{\mathrm{c}}$, \\ Fernanda Oliveira ${ }^{\mathrm{b}}$, Renata P. Limberger ${ }^{\mathrm{b}}$, Flavio Pechansky ${ }^{\mathrm{b}}$ \\ a Department of Health Information, Oswaldo Cruz Foundation, Rio de Janeiro, Brazil \\ ${ }^{\mathrm{b}}$ Center for Drug and Alcohol Research, Federal University of Rio Grande do Sul and Hospital de Clínicas de Porto Alegre, Brazil

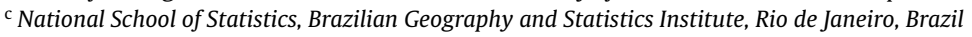

\section{A R T I C L E I N F O}

\section{Article history:}

Received 3 January 2013

Received in revised form 31 August 2013

Accepted 23 September 2013

\section{Keywords:}

Population-based surveys

Illicit drug use

Impaired driving

Alcohol outlets

Low and middle-income countries

\begin{abstract}
A B S T R A C T
Background: Driving under the influence of multiple substances is a public health concern, but there is little epidemiological data about their combined use and putative impact on driving in low and middleincome countries where traffic crashes have been clustering in recent years. The aim of this study is to estimate the prevalence of alcohol and drug use - as well as their associated factors - among drivers in the context of alcohol outlets (AOs).

Methods: A probability three-stage sample survey was conducted in Porto Alegre, Brazil. Individuals who were leaving AO were screened, with the selection of 683 drivers who met the inclusion criteria. Drivers answered a structured interview, were breathalyzed, and had their saliva collected for drug screening. Prevalences were assessed using domain estimation and logistic regression models assessed covariates associated with substance use.

Findings: Benzodiazepines 3.9\% (SE 2.13) and cocaine 3.8\% (SE 1.3) were the most frequently detected drugs in saliva. Among drivers who were going to drive, $11 \%$ had at least one drug identified by the saliva drug screening, $0.4 \%$ two, and $0.1 \%$ three drugs in addition to alcohol. In multivariable analyses, having a blood alcohol concentration $(B A C)>0.06 \%$ was found to be associated with a 3.64 times (CI 95\% 1.79-7.39) higher chance of drug detection, compared with interviewees with lower BACs.

Conclusions: To drive under the influence of multiple substances is likely to be found in this setting, highlighting an association between harmful patterns of consume of alcohol and the misuse of other substances.
\end{abstract}

(c) 2013 Elsevier Ltd. All rights reserved.

\section{Introduction}

Substance misuse is a major public health issue worldwide. Cannabis is by far the most widely used illicit drug, followed by amphetamines, opiates, and cocaine (UNODC, 2011). In the last ten years different studies have been assessing the consequences of drug (mis)use among drivers (Bernhoft et al., 2005; Elliott et al., 2009; Longo et al., 2000; Senna et al., 2010; Zhuo et al., 2010), especially in high-income countries, where a stabilization of the prevalence of driving under the influence of alcohol has been observed (Drummer et al., 2003; Gjerde et al., 2011).

Even though cannabis is the most prevalent drug found among drivers - and its prevalence seems to be increasing (Fergusson

\footnotetext{
* Corresponding author at: Oswaldo Cruz Foundation - FIOCRUZ, Biblioteca de Manguinhos Suite 229, Av. Brasil 4365, Rio de Janeiro 21045-900, Brazil.

E-mail address: raqueldeboni@msn.com (R.B. De Boni).
}

et al., 2008; Johnson et al., 2012), a recent study conducted in Australia by Chu et al. (2012) documented a $8 \%$ point prevalence for cocaine in 853 oral fluid samples collected from drivers, and Mura et al. reported high prevalences of both cocaine and amphetamines among injured drivers in a study carried out in France (Mura et al., 2006). Evidence on how every illicit drug affects, as well as their combined use, driving abilities remains far from comprehensive. Notwithstanding, most studies have found that combinations of illicit drug use and alcohol increase the risk of traffic accidents, as revised by Penning et al. (2010).

Brazil is the largest South American country and ranks fifth in terms of annual road absolute traffic deaths (around 36,000 in 2006), with 18 deaths per 100,000 inhabitants (WHO, 2009). The country has experiencing a fast economic growth and progressive motorization. Traffic accidents were estimated to be the fourth cause of premature death in 2010 (Institute for Health Metrics and Evaluation, 2012). General population data on the prevalence of alcohol related traffic deaths are far for complete and most results 
come from local studies. For example, in a study conducted in São Paulo, $42.3 \%$ of fatal injured drivers blood samples had blood alcohol concentrations (BACs) above $0.6 \mathrm{~g} / \mathrm{L}$ (de Carvalho Ponce et al., 2011). In another study, from Porto Alegre, alcohol was found in blood samples from $32.2 \%$ of the accident victims, whereas substances other than alcohol were found in about $11 \%$ of the samples (Stampe et al., 2010).

Impaired driving laws were changed in 2008, when a alcohol zero tolerance legislation was implemented, but enforcement of people driving under the influence of alcohol remains uneven and little regulation has been implemented in respect to other drugs (Pechansky and Chandran, 2012).

Studies with specific populations - such as truck drivers - have made evident high prevalences for amphetamines (Nascimento and Silva, 2007; Souza and Reimão, 2005) and cocaine (Leyton et al., 2012; Silva et al., 2003). Data from emergency rooms in Porto Alegre have documented a higher prevalence rate of cannabis/cocaine use than alcohol among injured drivers (De Boni et al., 2011). These high, combined, prevalences for different substances impose a complex challenge for policies aiming to reduce traffic-related deaths in Brazil.

Accordingly to the literature (Furr-Holden et al., 2006; Siliquini et al., 2010) and to our own empirical findings, driving after drinking is frequent among drivers who drunk on alcohol outlets (De Boni et al., 2012), and the distribution and characteristics of drivers who used cocaine and benzodiazepines markedly differ in highand low-alcohol outlet concentration areas. The present paper estimates the combined use of alcohol and drugs among drivers, as well as assesses its associated factors.

\section{Methods}

This study is a post hoc exploratory analysis profiting from a probability three-stage sampling survey conducted in Porto Alegre, Southern Brazil. As described in detail elsewhere (De Boni et al., 2012), 3118 individuals who were leaving AO were approached, 683 met inclusion criteria and were interviewed. Inclusion criteria were as follows: to be 18 years or more, to live in Porto Alegre, to have driven a motor vehicle in the previous 12 months, and to have been drinking on the premises of an alcohol outlet ( $\mathrm{AO}$, used here to represent establishments where people can drink on premises, such as bars, restaurants, pubs, discos) at the time of interview. Refusal rate was 5.6\% $(n=41)$. Data were collected between April and December 2009.

The following variables were analyzed in this manuscript:

High AO concentration areas were defined through Kernel density estimator, as described elsewhere (De Boni et al., 2013) and constituted one given geographic stratum in the sample design. Kernel estimation is a spatial smoothing method for point data used to detect "hot spots" of a given event of interest (Bailey and Gatrell, 1995).

Demographics were obtained with the application of a structured questionnaire. Driver destination was assessed through the question as follows: "Where are you going now?" and the answer was categorized as "home" (own, of family or friends), "work" (including school), and "bar, restaurant, party".

Intention to drive was assessed through the question as follows: "Are you going to drive in the next 60 minutes?"

DUI situations were assessed through the questions: "In the last 12 months, did you drive after drinking any alcohol beverage?" and "Have you ever been a passenger of a DUI driver in your lifetime?" and "Did you have any traffic crash (TC), which required any kind of medical assistance in your lifetime?"
Respondent opinion about the law (i.e. the legislation regulating DUI in Brazil, passed as a federal law in 2008; possible answers being: "in favor of", "against it", and "Does not know").

Alcohol abuse and/or dependence were assessed by "The Alcohol Use Disorders Identification Test" (AUDIT). The AUDIT score was dichotomized in under and over 8 , since scores above 8 (eight) have been associated with harmful alcohol use (Babor et al., 2001). Binge drinking in the previous year was evaluated by asking the question: "In the last year, did you drink 5 or more drinks (male) or 4 or more drinks (female) in about $2 \mathrm{~h}$ ?" (NIAAA, 2004).

$B A C$ was assessed using a calibrated breathalyzer (model ALCOSENSOR IVTM, Intoximeters Inc., Devon, UK). BAC results were dichotomized as follows: below $0.06 \%$ and equal/above $0.06 \%$. This is the cut-off for a criminal offense on DUI in the country (even though any positive concentration is considered an infraction). Saliva samples: oral fluid samples were obtained using a collection device (QuantisalTM, Immunalysis Corporation, Pomona, CA, USA), which uses a pad placed between the subject's cheek and gum. After collecting $1 \mathrm{~mL}$ of oral fluid, the pad was transferred to a vial containing $3 \mathrm{~mL}$ of buffering solution, capped and labeled, and transferred to the laboratory using containers with temperature monitored at approximately $5^{\circ} \mathrm{C}$ for no more than 2 days after sample collection. Samples were kept in the laboratory at $-80^{\circ} \mathrm{C}$ until analyzed. Due to budget constraints, cocaine and benzoylecgonine (BZE), tetrahydrocannabinol (THC) and benzodiazepines, the three most frequently used substances, as made evident by national surveys, were screened (CEBRID - Centro Brasileiro de Informação sobre Drogas Psicotrópicas, 2006). Ecstasy was also screened given the anecdotal reports of its increasing prevalence in the country in recent years (Pechansky and Remy et al., 2011). ELISA (Enzyme Linked Immuno Sorbent Assay) kits purchased from Immunalysis Corp. (Pomona, CA, USA) were used. Plate reading was conducted by spectrophotometer Anthos Zenyth 200rt (Wals, Austria). The tests were conducted following the recommendations of the manufacturer. Considering the recommended cut-offs of $50 \mathrm{ng} / \mathrm{mL}$ (BZE and benzodiazepines), $4 \mathrm{ng} / \mathrm{mL}$ (THC).

\subsection{Ethical aspects}

Informed consent was verbal, as approved by the IRB in charge of evaluating the study (HCPA IRB 06-012).

\subsection{Data analysis}

Analyses were performed with the help of R open source software, using its Survey library (Lumley, 2008, 2010). An object comprising sample design and weight calibration residuals was created to perform all subsequent analyses.

Prevalence and corresponding standard errors (SE) for those who had any positive drug testing or not were calculated using domain estimation (Cochran, 1977). Pearson's Chi-square homogeneity test with the Rao-Scott adjustment (Rao and Scott, 1984) was used to test the homogeneity of distributions across the two groups. Respecting calibration variables (for which the standard errors must be zero when using calibrated weights), test statistics were estimated using the design sample weights, based on the inverse of the probability to be included in the sample.

Two logistic regression models were fitted to data considering as outcome the use of any drug, besides alcohol. In Model 1, all variables with $p<0.20$ in bivariate analysis were included. In model 2 variables that had been found to be significantly different in bivariate analysis comparing drivers who provided or not the saliva test were also included in the model. 


\section{Results}

Refusal rate for providing a saliva test was $23 \%$. Table 1 shows the comparison of individuals who provided and those who refused to provide saliva samples.

The prevalence of drug use among drivers who drank was as follows: benzodiazepines 3.9\% (SE 2.13); cocaine 3.8\% (SE 1.3), THC $2.9 \%$ (SE 1.3), and ecstasy $0.2 \%$ (SE 0.1). Among drivers who were going to drive, $11 \%$ had one, $0.4 \%$ two, and $0.1 \%$ three different substances identified by saliva screening in addition to alcohol.

Individuals who had used drugs were similar to those who had drank only: they were mostly male, over 30 years old, and had a favorable opinion about the law against drinking and driving, irrespectively of the fact a substantial proportion of them were found to have higher prevalence of BAC over 0.06, as can be seen in Table 2 .

In the final logistic regression models, the only covariate found to be independently associated with drug use was to have a high BAC level, as can be seen in Table 3.

\section{Discussion}

There are few studies in the literature evaluating drug use among drivers in the context of settings with different alcohol outlets densities and most of them have used convenience samples. Targeted populations vary substantially, comprising data obtained from samples representative of the universe of people who drive (Gjerde et al., 2008; Johnson et al., 2012), most-at-risk drivers (Appenzeller et al., 2005), non-fatal victims hospitalized for their injuries (Bogstrand et al., 2012), and fatal traffic accidents victims (Gjerde et al., 2011). However, to better understand psychoactive drugs use in the very places where individuals drink and eventually drive in a subsequent moment is key to formulate and evaluate public policies aiming to control drug use and drug driving. Some of our study strengths include: to use a probabilistic sample and objective drug screening measures. To the best of authors' knowledge this is the first study in Latin America with these characteristics.

Brazilian legislation and actions aiming to prevent driving under the influence of substances other than alcohol are incipient and have to be fully regulated yet (current legislation refers to "psychoactive drugs", without any further specification and/or regulation), unlike most high-income countries (Chu et al., 2012; Drummer et al., 2012). In Brazil, saliva and/or urine drug screening have not be used by routine screening procedures, but rather constitute a rare exception in the context of urban/road traffic, working settings, among people under substitution therapy or on probation. Considering such pronounced differences, cross-cultural comparisons remain tentative.

The results show that cocaine was the most frequent illicit drug, unlike most international reports and Brazilian data from morgues/coroner reports (de Carvalho Ponce et al., 2011; Stampe et al., 2010) where cannabis prevalence rate was found to be higher than the prevalences for any other illicit drug. To have drunk in the outlet was an inclusion criterion of our study and the odds of alcohol-cocaine comorbid disorders are usually higher than alcohol-cannabis comorbid disorders (Stinson et al., 2005). A $\mathrm{BAC}>0.06 \%$ was found to be independently associated with the use of any other substance, what seems to characterize polyuse among heavy/dependent users of alcohol, as discussed by Appenzeller et al. (2005). This finding has two major implications for policymaking and traffic security: people with high BACs should be further screened for substances other than alcohol. Also, better integrated initiatives targeting alcohol and other substances misuse and driving should be implemented, comprising health education, promotion of safer driving, and agile referral and treatment of alcohol and substance harmful use and dependence. Referral for treatment and treatment provision for people who were found to be drinking/using substances has been erratic in Brazil and most initiatives are limited to law enforcement and eventual referral to short safer driving courses.

Notwithstanding, 3\% of the interviewees who provided biological samples tested positive for THC. The latter has been associated with impaired driving by different studies (Alvarez et al., 2007; Bédard et al., 2007). Driving under the influence of substances other than alcohol has been assessed by different studies, worldwide. The combination of high BAC levels and cannabis suggest our interviewees were likely to be involved a traffic accident.

We made evident differential prevalences of benzodiazepines and cocaine in areas with a high- (vs. low-) density of alcohol outlets. Cocaine was found to be especially prevalent in highdensity areas, whereas benzodiazepines were most frequently identified in low-density areas (De Boni et al., 2013). This may suggest that individuals with different drug consuming patterns may present not only different individual characteristics but tend to cluster in different settings, as discussed in Maxwell's study (2012), carried out in Texas, US. Additional, unmeasured, variables, such as psychiatric comorbidity or other medical conditions (such as type 1 diabetes) are likely to be associated with both substance misuse and accidents, and should be further explored (Faller et al., 2012).

Our study may have underestimated the actual prevalence of substances other than alcohol in consequence of the relatively high refusal rate in providing saliva for the saliva tests (21.3\%). The differences between individuals who did and who did not agree to be screened were found to be associated with socioeconomic status. Refusals were more frequent among those with higher educational levels and those with a valid driver's license. We hypothesize those subjects were particularly aware of the untoward consequences of a positive result in terms of being penalized for illicit drug possession and/or the potential risk of losing their driver's license. In this study, as well as in a previous study of our group (De Boni et al., 2011) targeting drivers recruited in Emergency rooms in consequence of traffic accidents, approximately $10 \%$ of them reported to have driven without a valid license. Such "informal" drivers usually belong to the so-called emergent low middle-class (since most people from poorer strata rather use public transportation). This population usually engages in activities which take place under the radar, such as working in the informal market, driving without a valid document on car ownership, and living in houses not formally registered in the official real state market.

The study has many limitations, including the small sample size for rare domain estimation. The study sample size was calculated in order to provide an adequate precision respecting its primary aim (alcohol vs. driving under its influence), but not respecting substances other than alcohol. For such small domains, the estimates precision precluded the differential assessment of specific substances, such as cannabis and cocaine, which may be associated with different harms and risks, as discussed by Maxwell (2012).

Due to budget constraints, we have screened saliva samples for four substances, which have been highlighted by the Brazilian literature as the key ones. Despite the fact amphetamines and amphetamine-like substances, such as fenproporex, diethylpropion and methylphenidate have been found to be prevalent among Brazilian truck drivers (Leyton et al., 2012) and in some assessments of general road drivers (Zancanaro et al., 2012), in this specific study we did not screen saliva samples for such substances. Future studies should screen saliva/urine for amphetamines/amphetamine-like substance among urban drivers.

The frequently observed high correspondence of drug concentrations in saliva to blood and behavioral and physiological effects, makes oral fluid an attractive matrix for use in detection of recent drug use, being recommended in the DUI tests (Walsh et al., 2008). 
Table 1

Comparison on individuals who provided or refused saliva tests.

\begin{tabular}{|c|c|c|c|c|c|}
\hline & \multicolumn{2}{|c|}{ Provided saliva test } & \multicolumn{2}{|c|}{ Refused saliva test } & \multirow[t]{2}{*}{$p$-Value ( $\chi^{2}$ Rao-Scott adjusted) } \\
\hline & $\%$ & SE & $\%$ & SE & \\
\hline Outlet concentration area & & & & & 0.127 \\
\hline High concentration & 20.6 & 1.2 & 28.9 & 4.6 & \\
\hline Low concentration & 79.4 & 1.2 & 71.0 & 4.6 & \\
\hline Male & 76.5 & 1.6 & 74.4 & 4.9 & 0.747 \\
\hline Age & & & & & 0.222 \\
\hline $18-29$ & 34.7 & 2.1 & 23.6 & 6.3 & \\
\hline 30 or more & 65.3 & 2.1 & 76.4 & 6.3 & \\
\hline Schooling & & & & & 0.012 \\
\hline Fundamental/high school & 60.2 & 4.9 & 41.2 & 8.1 & \\
\hline More than high school & 39.8 & 4.9 & 58.8 & 8.1 & \\
\hline Have a driver license & 88.1 & 2.8 & 96.9 & 1.4 & 0.007 \\
\hline Weekend & & & & & 0.018 \\
\hline Yes & 39.3 & 3.2 & 55.8 & 6.1 & \\
\hline No & 60.6 & 3.2 & 44.1 & 6.1 & \\
\hline Time & & & & & 0.077 \\
\hline 21-9h & 40.0 & 5.9 & 53.2 & 8.4 & \\
\hline $9-21 \mathrm{~h}$ & 59.9 & 5.9 & 46.8 & 8.4 & \\
\hline $\mathrm{BAC}>0.06$ & 33.6 & 4.5 & 35.1 & 8.9 & 0.883 \\
\hline AUDIT $>8$ & 54.4 & 5.9 & 61.6 & 7.4 & 0.485 \\
\hline Binge drinking & 64.3 & 8.6 & 74.2 & 6.8 & 0.454 \\
\hline Going to drive in $60 \mathrm{~min}$ & 54.8 & 1.7 & 61.1 & 5.4 & 0.383 \\
\hline Favorable opinion on the new traffic law & 65.2 & 5.2 & 66.4 & 7.2 & 0.872 \\
\hline
\end{tabular}

However, drugs and metabolites can generally be detected for a period of several hours to several days following drug exposure (Cone and Huestis, 2007), and the interpretation of oral fluid results in the DUI tests presents some difficult challenges that should be considered in the context of program requirements and a broad scientific, such as a wide intra and inter-individual variation and counterclockwise hysteresis. The Cone and Huestis (2007) review delineates many of the chemical and metabolic processes involved in the disposition of drugs and metabolites in oral fluid that are important to the appropriate interpretation of oral fluid tests and can be used as a general guidelines for understanding the significance of oral fluid tests.
Last but not least, the study did not assess people who misuse substances and did not drink alcohol and no definitive conclusions can be inferred for populations driving in major urban areas other than Porto Alegre since contextual variables are specific for each urban setting. Notwithstanding, our study strongly suggests that individuals from different countries/cities drinking at AO may be under high risk for impaired driving. The literature on it has been scarce and has been almost exclusively based on non-probability samples. Such complex combination of increased risks and scarcity of sound evidence is of great concern and speaks in favor of additional studies on different studies, profiting from probability-samples.

Table 2

Comparison on demographics and risk factors for traffic accidents between individuals who have/ have not used drugs.

\begin{tabular}{|c|c|c|c|c|c|}
\hline & \multicolumn{2}{|c|}{ Alcohol alone } & \multicolumn{2}{|c|}{ Alcohol + some drug } & \multirow[t]{2}{*}{$p$-Value ( $\chi^{2}$ Rao-Scott adjusted) } \\
\hline & $\%$ & SE & $\%$ & SE & \\
\hline High outlet area & 20.4 & 1.6 & 26,2 & 10.0 & 0.585 \\
\hline Male & 75.5 & 1.9 & 77.6 & 10.6 & 0.859 \\
\hline Age & & & & & 0.772 \\
\hline $18-29$ years & 35.5 & 2.3 & 38.8 & 11.2 & \\
\hline 30 or more & 64.5 & 2.3 & 61.2 & 11.2 & \\
\hline Schooling & & & & & 0.323 \\
\hline Fundamental/high school & 60.3 & 5.4 & 49.3 & 9.9 & \\
\hline More than high school & 39.7 & 5.4 & 50.7 & 9.9 & \\
\hline Have a driver license & 86.8 & 3.2 & 94,9 & 3.4 & 0.201 \\
\hline Weekend & & & & & 0.671 \\
\hline Yes & 37.4 & 3.2 & 42.2 & 11.4 & \\
\hline No & 62.5 & 3.2 & 57.8 & 11.4 & \\
\hline Time & & & & & 0.754 \\
\hline 21-9h & 40.6 & 6.2 & 45.9 & 16.2 & \\
\hline 9-21 h & 59.3 & 6.2 & 54.1 & 16.2 & \\
\hline $\mathrm{BAC}>0.06$ & 31.7 & 4.9 & 58.8 & 9,3 & 0.008 \\
\hline AUDIT > 8 & 56.4 & 7.7 & 49.8 & 8.9 & 0.334 \\
\hline Binge drinking & 61.9 & 9.2 & 72.9 & 10.2 & 0.356 \\
\hline Going to drive in $60 \mathrm{~min}$ & 54.3 & 2.3 & 59.7 & 13.4 & 0.738 \\
\hline Going to & & & & & 0.035 \\
\hline Work & 15.9 & 1.9 & 6.6 & 2.9 & \\
\hline Home & 73.6 & 3.8 & 89.8 & 4.1 & \\
\hline Bar, party & 10.5 & 2.9 & 3.6 & 2.4 & \\
\hline DUI last year & 87.1 & 2.2 & 78.3 & 10.9 & 0.361 \\
\hline DUI accident & 22.8 & 4.3 & 6.6 & 3.2 & 0.008 \\
\hline DUI passenger & 91.9 & 2.9 & 92.9 & 3.7 & 0.822 \\
\hline Breathlized before & 8.9 & 2.9 & 3.8 & 2.2 & 0.157 \\
\hline Favorable opinion on the new traffic law & 66.2 & 5.9 & 56.8 & 11.6 & 0.484 \\
\hline
\end{tabular}


Table 3

Associated factors for drug use after logistic regression.

\begin{tabular}{|c|c|c|c|}
\hline & Unadjusted OR (CI 95\%) & Model $1^{\mathrm{a}}$ & Model $2^{\mathrm{b}}$ \\
\hline Male & $1.12(0.31-4.07)$ & $1.47(0.33-6.56)$ & $1.63(0.39-6.87)$ \\
\hline Age & $0.98(0.93-1.03)$ & $0.97(0.92-1.01)$ & $0.97(0.93-1.01)$ \\
\hline Dont have a driver license & $0.35(0.06-1.83)$ & $0.20(0.04-0.7)$ & $0.2(0.02-1.84)$ \\
\hline \multicolumn{4}{|l|}{ Going to } \\
\hline Work & $0.34(0.12-0.94)$ & $0.23(0.06-0.81)$ & $0.24(0.05-1.00)$ \\
\hline Restaurant, party, bar & $0.28(0.06-1.28)$ & $0.55(0.10-2.97)$ & $0.56(0.11-2.9)$ \\
\hline Home & 1 & 1 & 1 \\
\hline $\mathrm{BAC}>0.06$ & $3.07(1.32-7.13)$ & $3.58(1.81-7.1)$ & $3.64(1.79-7.39)$ \\
\hline Previous DUI accident & $0.24(0.08-0.72)$ & $0.18(0.04-0.7)$ & $0.17(0.04-0.72)$ \\
\hline Never been stopped to breathalyze & $2.48(0.69-8.89)$ & $2.95(0.76-11.44)$ & $2.69(0.69-10.4)$ \\
\hline Schooling & & - & \\
\hline High school or more & $1.56(0.65-3.76)$ & - & $1.18(0.52-2.65)$ \\
\hline Less than high school & 1 & - & 1 \\
\hline Weekday & $0.82(0.33-2.03)$ & - & $0.99(0.31-3.16)$ \\
\hline Hour & $0.81(0.21-3.08)$ & - & $0.79(0.19-3.27)$ \\
\hline
\end{tabular}

a Model 1 includes variables that have $p<0.2$ in the comparison among drivers who have or have not used drugs, controlling for age and gender.

b Model 2 includes also variables with significant difference among drivers who provided or not saliva test.

Despite such limitations, disquieting levels of combined use of alcohol and other substances were made evident. Information on such users is sorely needed in Brazil. As mentioned before, drivers who misuse multiple substances were likely to present high relapse and arrest rates, such as in a study assessing Norwegian drivers (where polyusers were compared to drives who have exclusively used alcohol) (Christophersen et al., 2002). Traffic legislation in Brazil has been reformed in Brazil, in parallel with economic growth and the explosive increase of car and motorcycles in Brazilian roads and streets, but much remains to be done to effectively curb traffic injuries and deaths.

Comprehensive assessments of empirical data are essential components of any evidence-based legislation, as well as educational initiatives and treatment programs tailored to these at-risk populations.

\section{Acknowledgments}

This study was supported by National Secretariat for Drug and Alcohol Policies (SENAD TC 004/2007) and FIPE/HCPA (GPPG 006012). RDB has a FAPERJ/CAPES post-doctoral scholarship. FAPERJ and CNPq have supported FIB with career grants. RPL and FP have CNPq research fellowship.

\section{References}

Alvarez, F.J., Fierro, I., Del Río, M.C., 2007. Cannabis and driving: results from a general population survey. Forensic Sci. Int. 170, 111-116.

Appenzeller, B.M., Schneider, S., Yegles, M., Maul, A., Wennig, R., 2005. Drugs and chronic alcohol abuse in drivers. Forensic Sci. Int. 155, 83-90.

Babor, T., Higgins-Biddle, J., Saunders, J., Monteiro, M., 2001. AUDIT - The Alcohol Use Disorders Identification Test. Guidelines for Use in Primary Care. WHO, Geneva.

Bailey, T.C., Gatrell, A.C., 1995. Interactive Spatial Data Analysis. Addison Wesley Longman, Harlow, Essex.

Bernhoft, I.M., Steentoft, A., Johansen, S.S., Klitgaard, N.A., Larsen, L.B., Hansen, L.B., 2005. Drugs in injured drivers in Denmark. Forensic Sci. Int. 150, 181-189.

Bogstrand, S.T., Gjerde, H., Normann, P.T., Rossow, I., Ekeberg, O., 2012. Alcohol, psychoactive substances and non-fatal road traffic accidents - a case-control study. BMC Public Health 12, 734.

Bédard, M., Dubois, S., Weaver, B., 2007. The impact of cannabis on driving. Can. J. Public Health 98, 6-11.

CEBRID - Centro Brasileiro de Informação sobre Drogas Psicotrópicas, 2006. II Levantamento domiciliar sobre o uso de drogas psicotrópicas no Brasil: estudo envolvendo as 108 maiores cidades do país. UNIFESP - Universidade Federal de São Paulo, São Paulo, Available at: http://www.obid.senad.gov.br/portais/ OBID/index.php

Christophersen, A.S., Skurtveit, S., Grung, M., Mørland, J., 2002. Rearrest rates among Norwegian drugged drivers compared with drunken drivers. Drug Alcohol Depend. 66, 85-92.

Chu, M., Gerostamoulos, D., Beyer, J., Rodda, L., Boorman, M., Drummer, O.H., 2012. The incidence of drugs of impairment in oral fluid from random roadside testing. Forensic Sci. Int. 215, 28-31.

Cochran, W., 1977. Sampling Techniques. Wiley \& Sons, New York.
Cone, E.J., Huestis, M.A., 2007. Interpretation of oral fluid tests for drugs of abuse. Oral Based Diagn. 1098, 51-103.

De Boni, R., Bozzetti, M.C., Hilgert, J., Sousa, T., Von Diemen, L., Benzano, D., Menegon, G., Holmer, B., Duarte, P., Pechansky, o.C.F., 2011. Factors associated with alcohol and drug use among traffic crash victims in southern Brazil. Accid. Anal. Prev. $43,1408-1413$.

De Boni, R., do Nascimento Silva, P.L., Bastos, F.I., Pechansky, F., de Vasconcellos, M.T. 2012. Reaching the hard-to-reach: a probability sampling method for assessing prevalence of driving under the influence after drinking in alcohol outlets. PLoS ONE 7, e34104.

De Boni, R., Cruz, O.G., Weber, E., Hasenack, H., Lucatelli, L., Duarte, P., Gracie, R. Pechansky, F., Bastos, F.I., 2013. Traffic crashes and alcohol outlets in a Brazilian state capital. Traffic Inj. Prev. 14 (1), 86-91.

de Carvalho Ponce, J., Muñoz, D.R., Andreuccetti, G., de Carvalho, D.G., Leyton, V. 2011. Alcohol-related traffic accidents with fatal outcomes in the city of Sao Paulo. Accid. Anal. Prev. 43 (3), 782-787.

Drummer, O., Gerostamoulos, J., Batziris, H., Chu, M., Caplehorn, J., Robertson, M. Swann, P., 2003. The incidence of drugs in drivers killed in Australian road traffic crashes. Forensic Sci. Int. 134, 154-162.

Drummer, O.H., Kourtis, I., Beyer, J., Tayler, P., Boorman, M., Gerostamoulos, D. 2012. The prevalence of drugs in injured drivers. Forensic Sci Int. 215 (1-3) 14-17.

Elliott, S., Woolacott, H., Braithwaite, R., 2009. The prevalence of drugs and alcohol found in road traffic fatalities: a comparative study of victims. Sci. Justice 49, 19-23.

Faller, S., Webster, J., Leukefeld, C., Bumaguin, D., Duarte, P., De Boni, R., Pechansky, F., 2012. Psychiatric disorders among individuals who drive after the recent use of alcohol and drugs. Rev. Bras. Psiquiatr. 34, 314-320.

Fergusson, D.M., Horwood, L.J., Boden, J.M., 2008. Is driving under the influence of cannabis becoming a greater risk to driver safety than drink driving? Findings from a longitudinal study. Accid. Anal. Prev. 40, 1345-1350.

Furr-Holden, D., Voas, R.B., Kelley-Baker, T., Miller, B., 2006. Drug and alcoholimpaired driving among electronic music dance event attendees. Drug Alcohol Depend. 85, 83-86.

Gjerde, H., Normann, P.T., Christophersen, A.S., Samuelsen, S.O., Mørland, J., 2011. Alcohol, psychoactive drugs and fatal road traffic accidents in Norway: a case-control study. Accid. Anal. Prev. 43, 1197-1203.

Gjerde, H., Normann, P.T., Pettersen, B.S., Assum, T., Aldrin, M., Johansen, U., Kristoffersen, L., Øiestad, E.L., Christophersen, A.S., Mørland, J., 2008. Prevalence of alcohol and drugs among Norwegian motor vehicle drivers: a roadside survey. Accid. Anal. Prev. 40, 1765-1772.

Institute for Health Metrics and Evaluation, 2012. Global Burden of Disease: Country Profiles, Available at: http://www.healthmetricsandevaluation.org/sites/ default/files/country-profiles/GBD\%20Country\%20Report\%20-\%20Brazil.pdf

Johnson, M.B., Kelley-Baker, T., Voas, R.B., Lacey, J.H., 2012. The prevalence of cannabis-involved driving in California. Drug Alcohol Depend. 123, 105-109.

Leyton, V., Sinagawa, D.M., Oliveira, K.C.B.G., Schmitz, W., Andreuccetti, G., De Martinis, B.S., Yonamine, M., Munoz, D.R., 2012. Amphetamine, cocaine and cannabinoids use among truck drivers on the roads in the State of Sao Paulo, Brazil. Forensic Sci. Int. 215, 25-27.

Longo, M.C., Hunter, C.E., Lokan, R.J., White, J.M., White, M.A., 2000. The prevalence of alcohol, cannabinoids, benzodiazepines and stimulants amongst injured drivers and their role in driver culpability - Part II: the relationship between drug prevalence and drug concentration, and driver culpability. Accid. Anal. Prev. 32, 623-632.

Lumley, T., 2008. Survey: Analysis of Complex Survey Samples. p. R package, Washington.

Lumley, T., 2010. Complex Surveys: A Guide to Analysis Using R. John Wiley \& sons, New York

Maxwell, J.C., 2012. Drunk versus drugged: how different are the drivers? Drug Alcohol Depend. 121, 68-72. 
142

R.B. De Boni et al. / Accident Analysis and Prevention 62 (2014) 137-142

Mura, P., Chatelain, C., Dumestre, V., Gaulier, J.M., Ghysel, M.H., Lacroix, C., Kergueris, M.F., Lhermitte, A., Moulsma, M., Pepin, G., Vincent, F., Kintz, P., 2006. Use of drugs of abuse in less than 30-year-old drivers killed in a road crash in France: a spectacular increase for cannabis, cocaine and amphetamines. Forensic Sci. Int. $160,168-172$.

Nascimento, E.C.N.E., Silva, J.P., 2007. Uso de álcool e anfetaminas entre caminhoneiros de estrada. Rev. Saude Publica 41, 290-293.

NIAAA, 2004. NIAAA council approves definition of binge drinking. In: NIAAA Newsletter. NIH, Bethesda.

Pechansky, F., Remy, L., Surratt, H.L., Kurtz, S.P., Rocha, T.B., Von Diemen, L., Bumaguin, D.B., Inciardi, J., 2011. Age of Sexual Initiation, psychiatric symptoms, and sexual risk behavior among ecstasy and LSD users in Porto Alegre, Brazil: a preliminary analysis. Drug Issues 41 (2), 217.

Pechansky, F., Chandran, A., 2012. Why don't northern American solutions to drinking and driving work in southern America? Addiction 107 (7), 1201-1206.

Penning, R., Veldstra, J., Daamen, A., Olivier, B., Verster, J., 2010. Drugs of abuse, driving and traffic safety. Curr. Drug Abuse Rev. 3, 23-32.

Rao, J.N.K., Scott, A.J., 1984. On chi-squared tests for multiway contingency tables with proportions estimated from survey data. Ann. Stat. 12, 46-60.

Senna, M.C., Augsburger, M., Aebi, B., Briellmann, T.A., Donze, N., Dubugnon, J.L., Iten, P.X., Staub, C., Sturm, W., Sutter, K., 2010. First nationwide study on driving under the influence of drugs in Switzerland. Forensic Sci. Int. 198, 11-16.

Siliquini, R., Piat, S.C., Alonso, F., Druart, A., Kedzia, M., Mollica, A., Siliquini, V., Vankov, D., Villerusa, A., Manzoli, L., Group, T., 2010. A European study on alcohol and drug use among young drivers: the TEND by night study design and methodology. BMC Public Health 10, 205.
Stampe, M.Z., Silva, H.H., Schroeter, D., De Boni, R., Pechansky, F., Camargo, J., et al., 2010. Traffic accidents with fatal victims autopsied at the Porto Alegre Medical Examiner's Office. In: Pechansky, F., Duarte, P.C.A.V., De Boni, R. (Eds.), Use of Alcohol and Other Drugs on Brazilian Roads and Other Studies. National Secretariat for Drugs Policies, Porto Alegre, pp. 78-83.

Stinson, F.S., Grant, B.F., Dawson, D.A., Ruan, W.J., Huang, B., Saha, T., 2005. Comorbidity between DSM-IV alcohol and specific drug use disorders in the United States: results from the National Epidemiologic Survey on Alcohol and Related Conditions. Drug Alcohol Depend. 80 (1), 105-116.

Silva, O.A., Greve, J.M.D., Yonamine, M., Leyton, V., 2003. Drug use by truck drivers in Brazil. Drugs Educ. Prev. Policy 10, 135-139.

Souza, J.C.P., Reimão, T.R., 2005. Sleep habits, sleepiness and accidents among truck drivers. Arq. Neuropsiquiatr. 63, 925-930.

UNODC, 2011. In: United Nations Publication, S.N.E.X. (Ed.), United Nations Office on Drugs and Crime - World Drug Report 2011

Walsh, J.M., Verstraete, A.G., Huestis, M.A., Mørland, J., 2008. Guidelines for research on drugged driving. Addiction 103, 1258-1268.

WHO, 2009. Global Status Report on Road Safety: Time for Action. WHO, Geneva,

Zancanaro, I., Limberger, R.P., Bohel, P.O., Dos Santos, M.K., De Boni, R.B., Pechansky, F., Caldas, E.D., 2012. Prescription and illicit psychoactive drugs in oral fluidLC-MS/MS method development and analysis of samples from Brazilian drivers. Forensic Sci. Int. 223 (1-3), 208-216.

Zhuo, X.Y., Cang, Y., Yan, H., Bu, J., Shen, B.H., 2010. The prevalence of drugs in motor vehicle accidents and traffic violations in Shanghai and neighboring cities. Accid. Anal. Prev. 42, 2179-2184. 